ARTICLE

\title{
Atomically precise nanoclusters with reversible isomeric transformation for rotary nanomotors
}

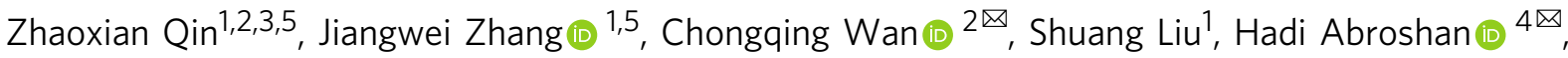 \\ Rongchao Jin (i) ${ }^{4 凶} \&$ Gao Li (iD ${ }^{1,3 凶}$
}

Thermal-stimuli responsive nanomaterials hold great promise in designing multifunctional intelligent devices for a wide range of applications. In this work, a reversible isomeric transformation in an atomically precise nanocluster is reported. We show that biicosahedral $\left[\mathrm{Au}_{13} \mathrm{Ag}_{12}\left(\mathrm{PPh}_{3}\right)_{10} \mathrm{Cl}_{8}\right] \mathrm{SbF}_{6}$ nanoclusters composed of two icosahedral $\mathrm{Au}_{7} \mathrm{Ag}_{6}$ units by sharing one common $\mathrm{Au}$ vertex can produce two temperature-responsive conformational isomers with complete reversibility, which forms the basis of a rotary nanomotor driven by temperature. Differential scanning calorimetry analysis on the reversible isomeric transformation demonstrates that the Gibbs free energy is the driving force for the transformation. This work offers a strategy for rational design and development of atomically precise nanomaterials via ligand tailoring and alloy engineering for a reversible stimuli-response behavior required for intelligent devices. The two temperature-driven, mutually convertible isomers of the nanoclusters open up an avenue to employ ultra-small nanoclusters $(1 \mathrm{~nm})$ for the design of thermal sensors and intelligent catalysts.

\footnotetext{
${ }^{1}$ State Key Laboratory of Catalysis, Dalian Institute of Chemical Physics, Chinese Academy of Sciences, 116023 Dalian, China. ${ }^{2}$ Beijing Key Laboratory for Optical Materials and Photonic Devices, Department of Chemistry, Capital Normal University, 100048 Beijing, China. ${ }^{3}$ University of Chinese Academy of Sciences, 100049 Beijing, China. ${ }^{4}$ Department of Chemistry, Carnegie Mellon University, Pittsburgh, PA 15213, USA. ${ }^{5}$ These authors contributed equally:

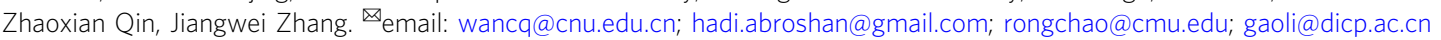


S timuli-responsive materials are at the forefront of technological innovations to fabricate the next-generation devices with "intelligent" performance ${ }^{1-3}$. To meet the selfactivation and -deactivation functionality requirements for smart materials, the stimuli-responsive behavior should be reversible. This can be satisfied by utilization of precise structural and phase transitions ${ }^{4-8}$. In particular, reversible conformational isomerism, a fundamental concept in molecular sciences that is commonly observed in organic molecules, offers a unique platform to prepare rotary motors at the nanoscale with atomistic precision.

Despite recent advances in controllable synthesis and structure determination of atomically precise nanoclusters ${ }^{9-18}$, the concept of reversible conformational isomerization for metal nanoclusters has not yet been explored. To date, irreversible structural isomerization of atomically precise nanoclusters has been reported in a few cases ${ }^{19-24}$. One case pertains to $\mathrm{Au}_{42}(\mathrm{TBBT})_{26}$ (TBBT $=4$-tert-butylbenzenethiolate) in the form of fcc and nonfcc frameworks that were synthesized via two different procedures ${ }^{19}$. However, the two isomeric structures of $\mathrm{Au}_{42}$ are "static" and cannot be reversibly transformed ${ }^{19}$. The same is true to the clusters prepared by Teo et al. ${ }^{20-23}$. One directional structural conversion from metastable $\mathrm{Au}_{38}\left(\mathrm{SC}_{2} \mathrm{H}_{4} \mathrm{Ph}\right)_{24}$ to thermodynamically stable biicosahedral $\mathrm{Au}_{38}\left(\mathrm{SC}_{2} \mathrm{H}_{4} \mathrm{Ph}\right)_{24}$ was reported to occur under thermal conditions, but unfortunately the reverse transformation could not occur ${ }^{24}$. Finally, while reversible transformation between $\mathrm{Au}_{28}\left(\mathrm{SC}_{6} \mathrm{H}_{11}\right)_{20}$ and $\mathrm{Au}_{28}\left(\mathrm{SPhC}_{4} \mathrm{H}_{9}\right)_{20}$ nanoclusters was realized by $\mathrm{Chen}$ et al., this case involves different surface-protecting ligands $\left(-\mathrm{SC}_{6} \mathrm{H}_{11}\right.$ vs. $\left.-\mathrm{SC}_{4} \mathrm{H}_{9}\right)$, so it does not strictly meet the definition of isomeric transformation ${ }^{25}$ and cannot be utilized for construction of nanomotors. Therefore, breakthroughs are still needed to precisely modulate the bonding structure of ultra-small nanoparticles to make their frameworks flexible for a facile molecular rotary nanomotor.

Herein, we report the discovery of a stimuli-responsive nanocluster that shows reversible conformational isomerism. The $\left[\mathrm{Au}_{13} \mathrm{Ag}_{12}\left(\mathrm{PPh}_{3}\right)_{10} \mathrm{Cl}_{8}\right]^{+}\left(\mathrm{SbF}_{6}\right)^{-}$nanocluster, hereafter abbreviated as $\mathrm{Au}_{13} \mathrm{Ag}_{12}$, presents two isomeric forms that can be selectively obtained by simply controlling the temperature (Fig. 1), hence forming the basis of a rotary nanomotor controlled by temperature. Through a combined approach of experiments, we have investigated the structure of the nanocluster and its

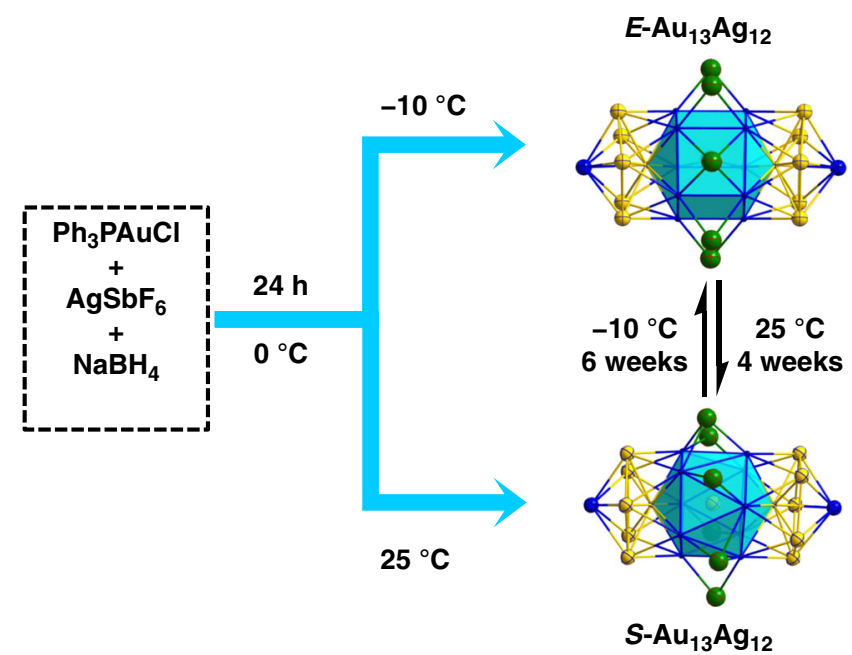

Fig. 1 Two isomers of the $\left[\mathrm{Au}_{13} \mathrm{Ag}_{12}\left(\mathrm{PPh}_{3}\right)_{10} \mathrm{Cl}_{8}\right]^{+}\left(\mathrm{SbF}_{6}\right)^{-}$nanocluster with thermally responsive transformation $(\boldsymbol{h}=$ hour). $E$ - eclipsed configuration, $\mathrm{S}$ - staggered configuration. Color code: Au: yellow; Ag: blue; $\mathrm{Cl}$ : green $(\mathrm{C}, \mathrm{H}, \mathrm{P}$, and some $\mathrm{Cl}$ are omitted for clarity). stimuli-responsive isomerization. The isomers possess distinct optical properties, which can be utilized for advancing intelligent sensors, catalysts, and controlled drug release in biomedical applications.

\section{Results}

Synthesis and characterization of $\mathrm{Au}_{13} \mathbf{A g}_{12}$ isomers. The $\mathrm{Au}_{13} \mathrm{Ag}_{12}$ nanocluster was synthesized by reduction of a mixed solution of $\mathrm{Ph}_{3} \mathrm{PAuCl}$ and $\mathrm{AgSbF}_{6}$ using $\mathrm{NaBH}_{4}$ in an ice bath (see Supplementary Methods). The nanoclusters were analyzed by electrospray ionization mass spectrometry (ESI-MS) in a positive mode. A weak mass peak at $m / z=6762.10$ and an intense one at $m / z=3362.56$ were observed in the mass spectrum (Fig. 2a), with the spacing of their isotope patterns being 1 and 0.5 (Fig. 2a, inset), hence, $1+$ and $2+$ charges, respectively. The two mass peaks correspond to $\left[\mathrm{Au}_{13} \mathrm{Ag}_{12}\left(\mathrm{PPh}_{3}\right)_{10} \mathrm{Cl}_{8}\right]^{+}$(theoretical $\mathrm{m} / \mathrm{z}: 6761.46 \mathrm{Da}$, deviation: $0.62 \mathrm{Da}$ ) and $\left[\mathrm{Au}_{13} \mathrm{Ag}_{12}\left(\mathrm{PPh}_{3}\right)_{10} \mathrm{Cl}_{7}\right]^{2+}$ (theoretical $\mathrm{m} / z$ : $3363.00 \mathrm{Da}$, deviation: $-0.44 \mathrm{Da}$ ), respectively, with the latter $\left(2+\right.$ ion) being formed via loss of $\mathrm{C} \mathrm{Cl}^{-}$from the intact $1+$ cluster during the ESI-MS analysis. X-ray crystallographic analysis (vide infra) confirmed homogeneous $\left[\mathrm{Au}_{13} \mathrm{Ag}_{12}\left(\mathrm{PPh}_{3}\right)_{10} \mathrm{Cl}_{8}\right]^{+}$, with no observation of $\left[\mathrm{Au}_{13} \mathrm{Ag}_{12}\left(\mathrm{PPh}_{3}\right)_{10} \mathrm{Cl}_{7}\right]^{2+}$. It is worth noting that loss of a $\mathrm{Cl}^{-}$ligand often occurs in ESI-MS analysis ${ }^{26}$. Therefore, the molecular formula of the synthesized nanoclusters is $\left[\mathrm{Au}_{13} \mathrm{Ag}_{12}\left(\mathrm{PPh}_{3}\right)_{10} \mathrm{Cl}_{8}\right]^{+}$, and the product is highly pure.

Surprisingly, two species were identified in the $\mathrm{Au}_{13} \mathrm{Ag}_{12}$ product by thin-layer chromatography (TLC) with $\mathrm{CH}_{2} \mathrm{Cl}_{2} /$ $\mathrm{CH}_{3} \mathrm{OH}(2: 1, \mathrm{v} / \mathrm{v})$ as the eluent ${ }^{27}$. The two distinct bands (Fig. 2b) indicate two isomers of $\mathrm{Au}_{13} \mathrm{Ag}_{12}$ since they share the same composition, hereafter denoted as $E$ - and $S-\mathrm{Au}_{13} \mathrm{Ag}_{12}$ (vide infra). The bands were cut out and extracted with $\mathrm{CH}_{2} \mathrm{Cl}_{2}$, and their optical spectra indeed show different profiles of the two isomers of $\mathrm{Au}_{13} \mathrm{Ag}_{12}$ (see Supplementary Fig. 1). The ultraviolet-visible (UV-vis) spectrum of the mixed isomers exhibit peaks at 324 , $361,420,500$, and $656 \mathrm{~nm}$. After TLC separation, the $E-\mathrm{Au}_{13} \mathrm{Ag}_{12}$ nanocluster shows three peaks at 361,418 , and $497 \mathrm{~nm}$, whereas the $S-\mathrm{Au}_{13} \mathrm{Ag}_{12}$ isomer shows four peaks at $330,423,510$, and $657 \mathrm{~nm}$. The energy gaps of the $S$ - and $E-A_{13} A_{12}$ isomers are 1.72 and $2.17 \mathrm{eV}$, respectively (see Supplementary Fig. 1, inset). Interestingly, the pure $S$ - and $E$ - $\mathrm{Au}_{13} \mathrm{Ag}_{12}$ isomers show different ${ }^{31} \mathrm{P}$ nuclear magnetic resonance (NMR) signals: $54.80 \mathrm{ppm}$ for $E$ $\mathrm{Au}_{13} \mathrm{Ag}_{12}$ and $57.36 \mathrm{ppm}$ for $\mathrm{S}-\mathrm{Au}_{13} \mathrm{Ag}_{12}$ using $\mathrm{Au}\left(\mathrm{PPh}_{3}\right) \mathrm{Cl}\left({ }^{31} \mathrm{P}\right.$ NMR: $33.13 \mathrm{ppm}$ ) as the internal reference (Fig. $2 \mathrm{c}$ and see Supplementary Fig. 2). It demonstrates that the $E-\mathrm{Au}_{13} \mathrm{Ag}_{12}$ and $S$ - $\mathrm{Au}_{13} \mathrm{Ag}_{12}$ nanoclusters have different structures (vide infra).

Crystal structures. Furthermore, we found that keeping a fresh solution of the $\mathrm{Au}_{13} \mathrm{Ag}_{12}$ nanocluster containing both isomers at $25{ }^{\circ} \mathrm{C}$ for 4 weeks led to a solution containing only the $S$ $\mathrm{Au}_{13} \mathrm{Ag}_{12}$ isomer. In contrast, under $-10{ }^{\circ} \mathrm{C}$ the same isomeric mixture completely transforms to the $E-\mathrm{Au}_{13} \mathrm{Ag}_{12}$ isomer after 6 weeks. Crystallizations of the $S-\mathrm{Au}_{13} \mathrm{Ag}_{12}$ and $E-\mathrm{Au}_{13} \mathrm{Ag}_{12}$ isomers were performed via a vapor diffusion method, followed by $\mathrm{X}$-ray diffraction analysis. The total structures of $\mathrm{S}-\mathrm{Au}_{13} \mathrm{Ag}_{12}$ and $E-\mathrm{Au}_{13} \mathrm{Ag}_{12}$ are displayed in Supplementary Figs. 3 and 4. For the core frameworks, each isomer is composed of two icosahedral $\mathrm{Au}_{7} \mathrm{Ag}_{6}$ units fused together by sharing a common vertex of $\mathrm{Au}$ (Fig. 3a). The two $\mathrm{Au}_{5}$ pentagons at the ends of the rod are ligated by ten phosphine ligands. Two $\mathrm{Cl}$ ligands bind with two apical Ag atoms. Six $\mathrm{Cl}$ ligands bridge the two icosahedra via bonding with 10 equatorial Ag atoms (see Supplementary Fig. 5).

The central $\mathrm{Au}$ atom (enlarged in Fig. $3 \mathrm{~b}$ ) connects the two $\mathrm{Au}_{7} \mathrm{Ag}_{6}$ icosahedra and serves as the pivot for the rotamerization of the metal configuration of the $\mathrm{Au}_{13} \mathrm{Ag}_{12}$. At $-10{ }^{\circ} \mathrm{C}$, the two $\mathrm{Au}_{7} \mathrm{Ag}_{6}$ units are in an eclipsed $(E)$ configuration with $D_{5 \mathrm{~h}}$ symmetry 

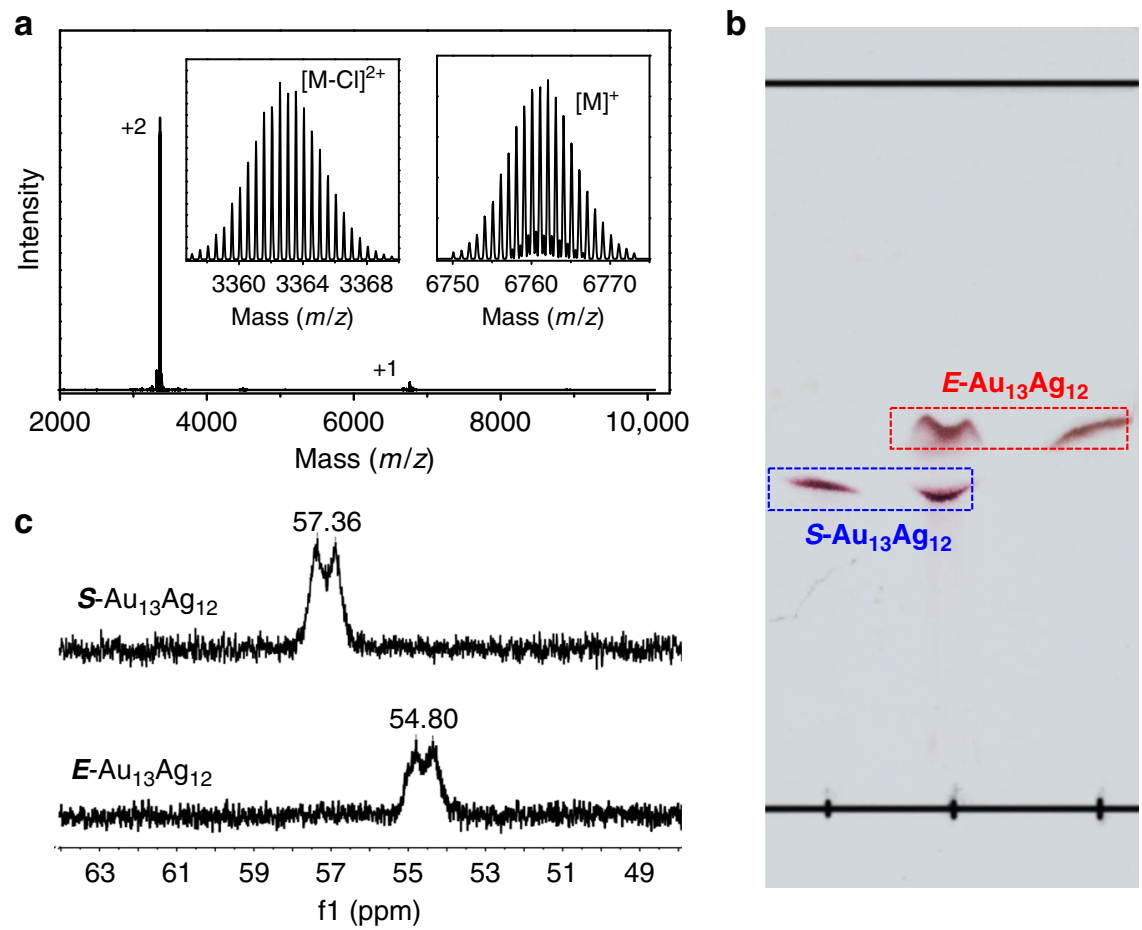

Fig. $\mathbf{2}$ Characterization of the $\mathbf{A u}_{\mathbf{1 3}} \mathbf{A g}_{\mathbf{1 2}}$ nanoclusters. a Positive-mode ESI mass spectrum of the as-synthesized $A u_{13} A g_{12} n a n o c l u s t e r$. ( $M=$ $\left.\mathrm{Au}_{13} \mathrm{Ag}_{12}\left(\mathrm{PPh}_{3}\right)_{10} \mathrm{Cl}_{8}\right)$ b Thin-layer chromatography separation of the $\mathrm{Au}_{13} \mathrm{Ag}_{12}$ using $\mathrm{CH}_{2} \mathrm{Cl}_{2} / \mathrm{CH}_{3} \mathrm{OH}(2: 1, \mathrm{v} / \mathrm{v})$ as an eluent. c ${ }^{31} \mathrm{P} \mathrm{NMR}$ spectra of the $\mathrm{S}-\mathrm{Au}_{13} \mathrm{Ag}_{12}$ and $\mathrm{E}-\mathrm{Au}_{13} \mathrm{Ag}_{12}$ in $\mathrm{CD}_{2} \mathrm{Cl}_{2}$.

Metal configuration, symmetry, and rotamerization
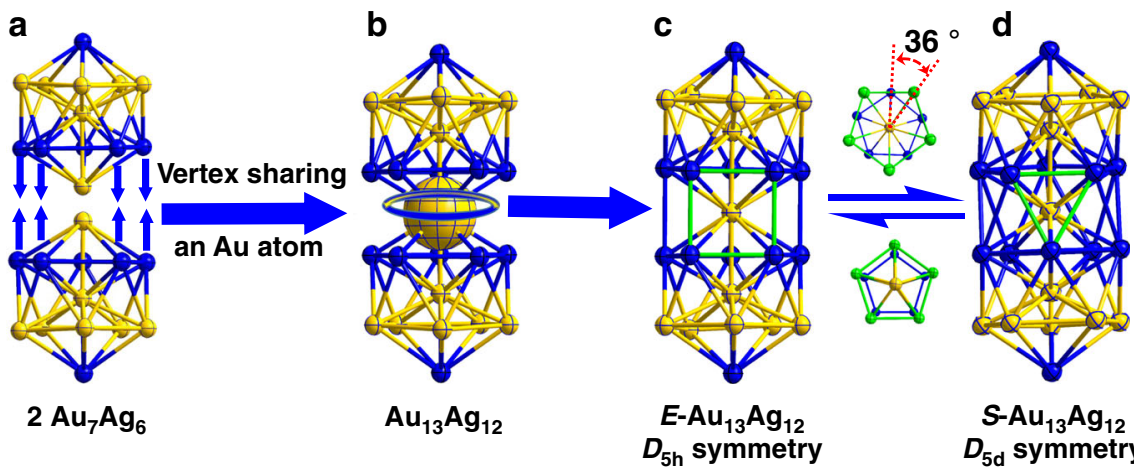

$\mathrm{S}-\mathrm{Au}_{13} \mathrm{Ag}_{12}$

$D_{5 d}$ symmetry

Fig. 3 Configuration of the $\mathbf{A u}_{\mathbf{1 3}} \mathbf{A g}_{\mathbf{1 2}}$ nanocluster. $\mathbf{a}, \mathbf{b}$ Two icosahedral $A u_{7} A g_{6}$ units share one common vertex of $A u$ to form the $A u_{13} A g_{12}$ nanocluster. c Metal configuration of E-isomer. d Metal configuration of S-isomer. Color code: Au: yellow; Ag: blue. Other atoms are omitted for clarity.

(i.e., $E-\mathrm{Au}_{13} \mathrm{Ag}_{12}$, Fig. $3 \mathrm{c}$ ), whereas at $25^{\circ} \mathrm{C}$ the two $\mathrm{Au}_{7} \mathrm{Ag}_{6}$ units rotate by about $36^{\circ}$ to form a staggered $(S)$ configuration with $D_{5 \mathrm{~d}}$ symmetry $\left(S-\mathrm{Au}_{13} \mathrm{Ag}_{12}\right.$, Fig. $\left.3 \mathrm{~d}\right)$. We note that, at the lower temperature $\left(-10^{\circ} \mathrm{C}\right)$, the $\mathrm{Au}_{13} \mathrm{Ag}_{12}$ nanocluster prefers to adapt the configuration with a higher symmetry. The six chloride ligandswhich bridge the two $\mathrm{Au}_{7} \mathrm{Ag}_{6}$ units-serve as the "belt" to drive the rotamerization, Fig. 4 . In the $E-\mathrm{Au}_{13} \mathrm{Ag}_{12}$ isomer, there are five $\mathrm{Cl}$ ligands with each being bonded with two silver atoms (d-mode). For the same isomer, there is also a $\mathrm{Cl}$ ligand that is bonded with four silver atoms (q-mode). In the $S-\mathrm{Au}_{13} \mathrm{Ag}_{12}$ isomer, four $\mathrm{Cl}$ ligands are in the $\mathrm{d}$-mode bonding, and two $\mathrm{Cl}$ ligands are each bonded with three silver atoms ( $\mathrm{t}$-mode).

Reversible transformation between the $\boldsymbol{E}$ - and $\boldsymbol{S}$ - isomer. The $E-\mathrm{Au}_{13} \mathrm{Ag}_{12}$ and $S-\mathrm{Au}_{13} \mathrm{Ag}_{12}$ isomers can be $100 \%$ selectively obtained at -10 and $25^{\circ} \mathrm{C}$, respectively. To test the reversibility of the isomeric transformation, we monitored the process by

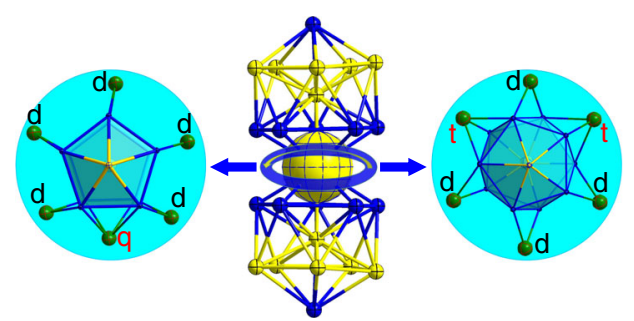

Fig. 4 Structures of $E$ - and $S-A_{13} A_{12}$ isomers from the top view. Doubly (d), triply ( $\mathrm{t}$ ), and quadruply (q) binding patterns of six equatorial $\mathrm{Cl}$ ligands bridging the two icosahedra. Color codes: Au: yellow; Ag: blue; Cl: green.

UV-vis absorption spectroscopy using the crystal sample of $E-\mathrm{Au}_{13} \mathrm{Ag}_{12}$ nanoclusters as the starting material. We first studied the $E-\mathrm{Au}_{13} \mathrm{Ag}_{12}$ nanocluster in a dichloromethane solution at $25^{\circ} \mathrm{C}$. The characteristic peak at $361 \mathrm{~nm}$ gradually decreased over 
time and simultaneously peaks at 330,423 , and $657 \mathrm{~nm}$ gradually increased. The peak at $418 \mathrm{~nm}$ also red-shifted to $510 \mathrm{~nm}$ during a period of 28 days, Fig. $5 \mathrm{a}$. The ${ }^{31} \mathrm{P}$ NMR test of the sample gave a doublet-splitting peak centered at 57.36 ppm (see Supplementary Figs. 6 and 7). These results indicate that the $E-A_{13} A_{12}$ isomer slowly converts to the $S-\mathrm{Au}_{13} \mathrm{Ag}_{12}$ isomer at $25^{\circ} \mathrm{C}$. We next studied the transformation of the as-obtained $S-\mathrm{Au}_{13} \mathrm{Ag}_{12}$ isomer at $-10^{\circ} \mathrm{C}$. The characteristic peaks at 330 and $657 \mathrm{~nm}$ disappeared after 42 days. Meanwhile, the peak at $361 \mathrm{~nm}$ increased and the peak at $510 \mathrm{~nm}$ blue-shifted to $418 \mathrm{~nm}$, demonstrating that the $S-\mathrm{Au}_{13} \mathrm{Ag}_{12}$ isomer transforms to the $E$ $\mathrm{Au}_{13} \mathrm{Ag}_{12}$ counterpart (Fig. 5b). This is further supported by
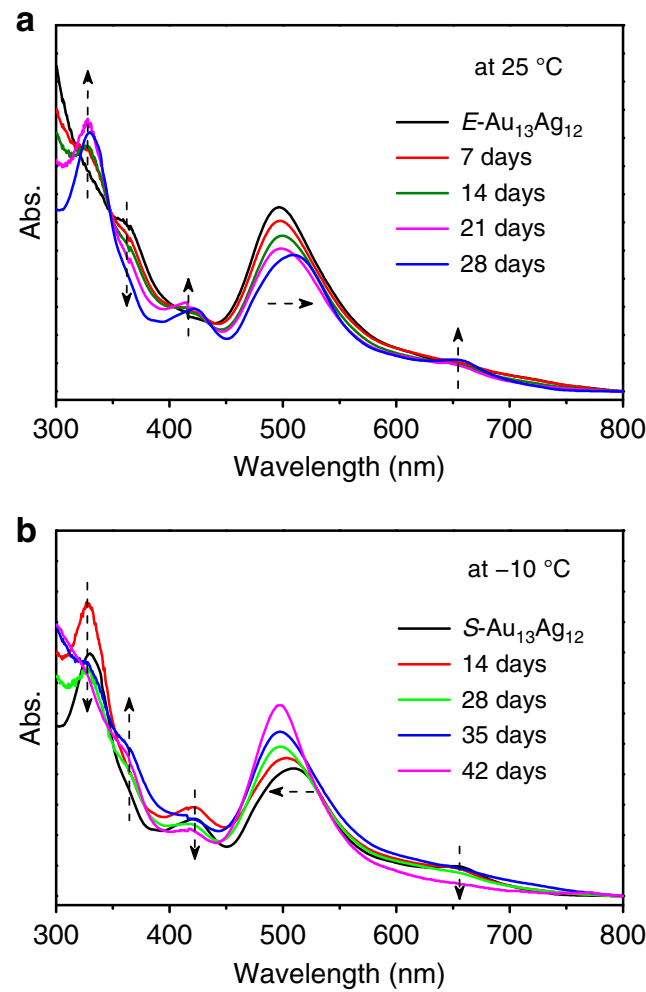

Fig. 5 UV-vis spectral evolution for the isomeric transformation of the nanoclusters. a $E-\mathrm{Au}_{13} \mathrm{Ag}_{12}$ conversion to $\mathrm{S}-\mathrm{Au}_{13} \mathrm{Ag}_{12}$ at $25^{\circ} \mathrm{C}$. b The as-obtained $\mathrm{S}-\mathrm{Au}_{13} \mathrm{Ag}_{12}$ conversion to $\mathrm{E}-\mathrm{Au}_{13} \mathrm{Ag}_{12}$ at $-10^{\circ} \mathrm{C}$.
${ }^{31} \mathrm{P}$ NMR analysis, as the NMR peak appears at $54.80 \mathrm{ppm}$ (see Supplementary Figs. 8 and 9). Of note, no byproduct was formed during the reversible transformation, evidenced by the ESI-MS tests (see Supplementary Figs. 10 and 11). These results imply that both isomers are stable, and the isomeric transformation process is reminiscent of typical phase transitions.

Differential scanning calorimeter (DSC) method was used to investigate the isomeric transformation process and the corresponding enthalpy ${ }^{28}$. Starting from the $S-\mathrm{Au}_{13} \mathrm{Ag}_{12}$ isomer, a negative peak centered at $79.6^{\circ} \mathrm{C}$ was observed during the DSC test, which points to endothermicity of the isomeric transformation of the $S-\mathrm{Au}_{13} \mathrm{Ag}_{12}$ to $E-\mathrm{Au}_{13} \mathrm{Ag}_{12}$ (Fig. 6a). Both UV-vis and ${ }^{31} \mathrm{P}$ NMR analyses indicate that the $S-\mathrm{Au}_{13} \mathrm{Ag}_{12}$ isomer was partially converted to the $E-A_{13} A_{12}$ isomer (see Supplementary Figs. 12 and 13). Furthermore, thermogravimetric analysis (TGA) revealed that the removal of $\mathrm{Cl}$ ligands from the nanoclusters occur at $175^{\circ} \mathrm{C}$ (weight loss of $\sim 3.7 \mathrm{wt} \%$, consistent with the expected value of $4.0 \mathrm{wt} \%)$, Fig. $6 \mathrm{~b}$. Subsequently, the phosphine ligands began to desorb at $\sim 210^{\circ} \mathrm{C}$, consistent with the desorption temperature reported for the phosphine-protected $\mathrm{Au}$ nanocluster ${ }^{28,29}$. The TGA results indicate that the $\mathrm{Au}_{13} \mathrm{Ag}_{12}$ nanoclusters are intact below $100{ }^{\circ} \mathrm{C}$ (see Supplementary Figs. 14 and 15); thus the observed endothermic process in the DSC analysis is solely associated with the isomeric transformation, rather than with any ligand loss.

Owning to the higher symmetry of the $E-A_{13} A_{12}\left(D_{5 h}\right)$ than the $S-A_{13} A_{12}\left(D_{5 \mathrm{~d}}\right)$, the nanocluster is a potential prototype of thermal molecular motor where Gibbs free energy serves as the driving force. In a previous work, Teo et al. ${ }^{20-23}$ synthesized two isomers of $\mathrm{Au}_{13} \mathrm{Ag}_{12}\left(\mathrm{PPh}_{3}\right)_{10} \mathrm{Br}_{8}$ nanoclusters; however, no isomeric rotamerization was observed, which can be attributed to the stronger $\mathrm{Ag}-\mathrm{Br}$ bonds than $\mathrm{Ag}-\mathrm{Cl}$. Our study shows that employing the $-\mathrm{Cl}$ ligand, instead of $-\mathrm{Br}$, leads to higher flexibility on Ag-halide bonds, which is essential and critical to achieve a more flexible cluster framework for the thermally responsive, reversible transformation between the $E-A_{13} A_{12}$ and $S-\mathrm{Au}_{13} \mathrm{Ag}_{12}$ isomers. Such a Cl-ligand-induced rotary nanomotor is simulated based on the experimental structures (see Supplementary Movie 1). For practical applications, the temperature will serve as the driving force.

In summary, two isomers of the biicosahedral $\left[\mathrm{Au}_{13} \mathrm{Ag}_{12}\left(\mathrm{PPh}_{3}\right)_{10} \mathrm{Cl}_{8}\right]^{+}$(counterion: $\left[\mathrm{SbF}_{6}\right]^{-}$) nanocluster (i.e., $S$ $\mathrm{Au}_{13} \mathrm{Ag}_{12}$ and $\left.E-\mathrm{Au}_{13} \mathrm{Ag}_{12}\right)$ are discovered, and these two isomers are reversibly transformable by controlling the temperature.

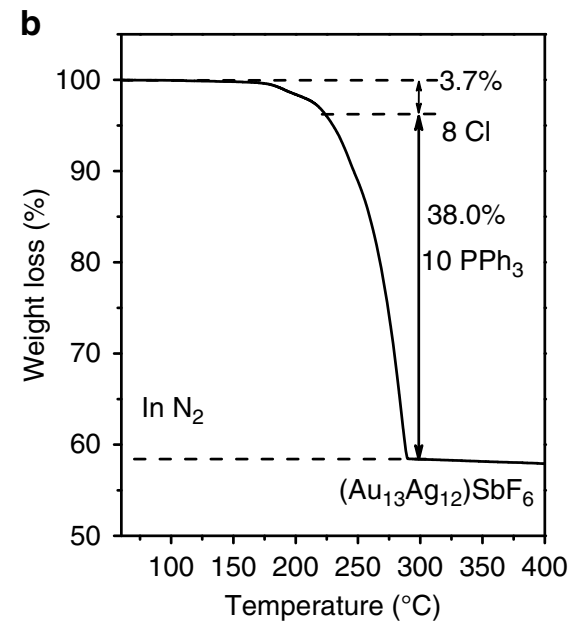

Fig. 6 Thermal analysis of the $\mathbf{A u}_{\mathbf{1 3}} \mathbf{A g}_{\mathbf{1 2}}$ nanoclusters. a DSC analysis for the conversion of the $S-A u_{13} A g_{12}$ to $E-A u_{13} A g_{12}$ under a $N_{2}$ atmosphere. $\mathbf{b}$ TGA test of the $\mathrm{Au}_{13} \mathrm{Ag}_{12}$ nanoclusters under a $\mathrm{N}_{2}$ atmosphere. 
The metal configuration of the $E-\mathrm{Au}_{13} \mathrm{Ag}_{12}$ isomer possesses a higher symmetry $\left(D_{5 \mathrm{~h}}\right)$ than that of the $S-\mathrm{Au}_{13} \mathrm{Ag}_{12}$ isomer $\left(D_{5 \mathrm{~d}}\right)$ and is preferably formed at low temperature $\left(-10^{\circ} \mathrm{C}\right)$. As the temperature increases to $25^{\circ} \mathrm{C}$, the $\mathrm{S}-\mathrm{Au}_{13} \mathrm{Ag}_{12}$ isomer (lower symmetry) is exclusively formed. This study shows that the alloying and ligand engineering (i.e., $\mathrm{Ag}$-halide bond) provide a rational strategy to make the framework of metal nanoclusters more flexible for achieving the conformational isomerism, which has the potential to be applied in designing intelligent molecular engines with Gibbs free energy as the driving force of the activity.

\section{Methods}

Synthesis of $\mathbf{A u}_{\mathbf{1 3}} \mathbf{A g}_{\mathbf{1 2}}$ nanoclusters. $\mathrm{Au}(\mathrm{I}) \mathrm{PPh}_{3} \mathrm{Cl}(25 \mathrm{mg}$, dissolved in $2 \mathrm{~mL}$ chloromethane/methanol with $v: v=1: 1)$ was mixed with $\mathrm{AgSbF}_{6}(17.2 \mathrm{mg}$, dissolved in $2 \mathrm{~mL}$ chloromethane/methanol with $v: v=1: 1$ ). The solution was stirred in dark and air atmosphere. Then the solution was cooled using an ice bath for $30 \mathrm{~min}$, followed by dropwise addition of $\mathrm{NaBH}_{4}$ solution $(2 \mathrm{mg}$, dissolved in $4 \mathrm{~mL}$ ice cold methanol). The mixture was kept in the dark and stirred for another $24 \mathrm{~h}$. Next, the temperature was increased slowly to $25^{\circ} \mathrm{C}$. The mixture was then dried via vacuum evaporation and washed with hexane $(2 \times 1 \mathrm{~mL})$, leaving a black solid. Finally, the black solid was dissolved in $2 \mathrm{~mL}$ dichloromethane/methanol $(v: v=1: 1)$ and centrifuged at $10,000 \mathrm{rpm}$ for $5 \mathrm{~min}$. Red, plate-like crystals of $E$ $\mathrm{Au}_{13} \mathrm{Ag}_{12}$ and $S-\mathrm{Au}_{13} \mathrm{Ag}_{12}$ were obtained via slow diffusion of diethyl ether into the cluster solution over 6 weeks at -10 or $25^{\circ} \mathrm{C}$. The yields are $26.0 \%$ for $E-\mathrm{Au}_{13} \mathrm{Ag}_{12}$ and $34.9 \%$ for $S-\mathrm{Au}_{13} \mathrm{Ag}_{12}$ based on the consumption of $\mathrm{Ph}_{3} \mathrm{PAuCl}$.

\section{Data availability}

The X-ray crystallographic coordinates for structures reported in this study have been deposited at the Cambridge Crystallographic Data Centre (CCDC), under deposition numbers 1888164-1888165. These data can be obtained free of charge from The Cambridge Crystallographic Data Centre via www.ccdc.cam.ac.uk/data_request/cif. The datasets generated and/or analyzed during this study are available from the corresponding author upon reasonable request.

Received: 2 February 2020; Accepted: 19 October 2020; Published online: 26 November 2020

\section{References}

1. Petermayer, C. \& Dube, H. Indigoid photoswitches: visible light responsive molecular tools. Acc. Chem. Res. 51, 1153-1163 (2018).

2. Wei, P. et al. Multiple yet controllable photoswitching in a single AIEgen system. J. Am. Chem. Soc. 140, 1966-1975 (2018).

3. Zhang, B. et al. Thermally-induced reversible structural isomerization in colloidal semiconductor CdS magic-size clusters. Nat. Commun. 9, 2499-2508 (2018).

4. Fan, X., Wang, J., Wu, K., Zhang, L. \& Zhang, J. Isomerism in titanium-oxo clusters: molecular anatase model with atomic structure and improved photocatalytic activity. Angew. Chem. Int. Ed. 58, 1320-1323 (2019).

5. Wang, H., Zhang, J. \& Xie, Z. Reversible photothermal isomerization of carborane-fused azaborole to borirane: synthesis and reactivity of carbenestabilized carborane-fused borirane. Angew. Chem. Int. Ed. 129, 9326-9329 (2017).

6. Sun, J. et al. Stimuli-directed dynamic reconfiguration in self-organized helical superstructures enabled by chemical kinetics of chiral molecular motors. Adv. Sci. 5, 1700613-1700621 (2018).

7. Zhang, J. et al. The proton-controlled synthesis of unprecedented diol functionalized Anderson-type POMs. Chem. Commun. 52, 2378-2381 (2016).

8. Zhang, J. et al. Unprecedented $\chi$ isomers of single-side triolfunctionalized Anderson polyoxometalates and their proton-controlled isomer transformation. Chem. Commun. 51, 9097-9100 (2015).

9. Konishi, K., Iwasaki, M. \& Shichibu, Y. Phosphine-ligated gold clusters with core+exo geometries: unique properties and interactions at the ligand-cluster interface. Acc. Chem. Res. 51, 3125-3133 (2018).

10. Cook, A. W. \& Hayton, T. W. Case studies in nanocluster synthesis and characterization: challenges and opportunities. Acc. Chem. Res. 51, 2456-2464 (2018).

11. Lei, Z., Wan, X.-K., Yuan, S.-F., Guan, Z.-J. \& Wang, Q.-M. Alkynyl approach toward the protection of metal nanoclusters. Acc. Chem. Res. 51, 2465-2474 (2018).

12. Yao, Q., Chen, T., Yuan, X. \& Xie, J. Toward total synthesis of thiolateprotected metal nanoclusters. Acc. Chem. Res. 51, 1338-1348 (2018).
13. Zheng, $\mathrm{K}$. et al. Motif-mediated $\mathrm{Au}_{25}(\mathrm{SPh})_{5}\left(\mathrm{PPh}_{3}\right)_{10} \mathrm{X}_{2}$ nanorods with conjugated electron delocalization. Nano Res. 12, 501-507 (2019).

14. Zhang, J. et al. Diphosphine-induced chiral propeller arrangement of gold nanoclusters for singlet oxygen photogeneration. Nano Res. 11, 5787-5798 (2018).

15. Nieto-Ortega, B. \& Bürgi, T. Vibrational properties of thiolate-protected gold nanoclusters. Acc. Chem. Res. 51, 2811-2819 (2018)

16. Chakraborty, P., Nag, A., Chakraborty, A. \& Pradeep, T. Approaching materials with atomic precision using supramolecular cluster assemblies. Acc. Chem. Res. 52, 2-11 (2019).

17. Zhou, M. et al. Three-orders-of-magnitude variation of carrier lifetimes with crystal phase of gold nanoclusters. Science 364, 279-282 (2019).

18. Jin, R., Zeng, C., Zhou, M. \& Chen, Y. Atomically precise colloidal metal nanoclusters and nanoparticles: fundamentals and opportunities. Chem. Rev. 116, 10346-10413 (2016).

19. Zhuang, S. et al. Fcc versus non-fcc structural isomerism of gold nanoparticles with kernel atom packing dependent photoluminescence. Angew. Chem. Int. Ed. 58, 4510-4514 (2019).

20. Teo, B. K. \& Zhang, H. Molecular machines: molecular structure of [(p$\left.\left.\mathrm{Tol}_{3} \mathrm{P}\right)_{10} \mathrm{Au}_{13} \mathrm{Ag}_{12} \mathrm{Cl}_{8}\right]\left(\mathrm{PF}_{6}\right)$-a cluster with a biicosahedral rotorlike metal core and an unusual arrangement of bridging ligands. Angew. Chem. Int. Ed. 31, 445-447 (1992).

21. Teo, B. K., Shi, X. B. \& Zhang, H. Cluster of clusters. Structure of a novel cluster $\left[\left(\mathrm{Ph}_{3} \mathrm{P}\right)_{10} \mathrm{Au}_{13} \mathrm{Ag}_{12} \mathrm{Br}_{8}\right]\left(\mathrm{SbF}_{6}\right)$ containing an exact staggered-eclipsedstaggered metal configuration: evidence of icosahedral units as building blocks. J. Am. Chem. Soc. 113, 4329-4331 (1991).

22. Teo, B. K., Shi, X. B. \& Zhang, H. Cluster rotamerism of a 25-metal-atom cluster $\left[\left(\mathrm{Ph}_{3} \mathrm{P}\right)_{10} \mathrm{Au}_{13} \mathrm{Ag}_{12} \mathrm{Br}_{8}\right]^{+}$monocation: a molecular rotary unit. J. Chem. Soc. Chem. Commun., 1195-1196 (1992).

23. Teo, B. K. \& Zhang, H. Cluster of clusters. Structure of a new 25-metal-atom cluster $\left[\left(\mathrm{p}-\mathrm{Tol}_{3} \mathrm{P}\right)_{10} \mathrm{Au}_{13} \mathrm{Ag}_{12} \mathrm{Cl}_{7}\right]\left(\mathrm{SbF}_{6}\right)_{2}$ containing a nearly staggeredeclipsed-staggered metal configuration and five doubly bridging ligands. Inorg. Chem. 30, 3115-3116 (1991).

24. Tian, S. et al. Structural isomerism in gold nanoparticles revealed by X-ray crystallography. Nat. Commun. 6, 8667-8672 (2015).

25. Chen, Y. et al. Isomerism in $\mathrm{Au}_{28}(\mathrm{SR})_{20}$ nanocluster and stable structures. J. Am. Chem. Soc. 138, 1482-1485 (2016).

26. Song, Y. et al. How a single electron affects the properties of the "nonsuperatom" $\mathrm{Au}_{25}$ nanoclusters. Chem. Mater. 28, 2609-2617 (2016).

27. Liao, L. et al. Quantitatively monitoring the size-focusing of Au nanoclusters and revealing what promotes the size transformation from $\mathrm{Au}_{44}(\mathrm{TBBT})_{28}$ to $\mathrm{Au}_{36}(\mathrm{TBBT})_{24}$. Anal. Chem. 88, 11297-11301 (2016).

28. Molard, Y. Clustomesogens: liquid crystalline hybrid nanomaterials containing functional metal nanoclusters. Acc. Chem. Res. 49, 1514-1523 (2016).

29. Liu, C., Abroshan, H., Yan, C., Li, G. \& Haruta, M. One-Pot synthesis of $\mathrm{Au}_{11}\left(\mathrm{PPh}_{2} \mathrm{Py}\right)_{7} \mathrm{Br}_{3}$ for the highly chemoselective hydrogenation of nitrobenzaldehyde. ACS Catal. 6, 92-99 (2016).

\section{Acknowledgements}

G.L. acknowledges financial support from the National Natural Science Foundation of China (No. 21701168) and Liaoning Revitalization Talents Program (XLYC1807121).

\section{Author contributions}

G.L., C.W., H.A., and R.J. conceived the work. Z.Q., J.Z., S.L., and G.L. performed the experiments. G.L., H.A., and R.J. wrote the manuscript. All authors discussed the results and commented on the manuscript.

\section{Competing interests}

The authors declare no competing interests.

\section{Additional information}

Supplementary information is available for this paper at https://doi.org/10.1038/s41467 020-19789-4.

Correspondence and requests for materials should be addressed to C.W., H.A., R.J. or G.L.

Peer review information Nature Communications thanks Yuichi Negishi and the other anonymous reviewer(s) for their contribution to the peer review of this work.

Reprints and permission information is available at http://www.nature.com/reprints

Publisher's note Springer Nature remains neutral with regard to jurisdictional claims in published maps and institutional affiliations. 
(c) (i) Open Access This article is licensed under a Creative Commons Attribution 4.0 International License, which permits use, sharing, adaptation, distribution and reproduction in any medium or format, as long as you give appropriate credit to the original author(s) and the source, provide a link to the Creative Commons license, and indicate if changes were made. The images or other third party material in this article are included in the article's Creative Commons license, unless indicated otherwise in a credit line to the material. If material is not included in the article's Creative Commons license and your intended use is not permitted by statutory regulation or exceeds the permitted use, you will need to obtain permission directly from the copyright holder. To view a copy of this license, visit http://creativecommons.org/ licenses/by/4.0/.

(C) The Author(s) 2020 